\title{
MODELING OF THE INTELLECTUAL SYSTEM'S WORK FOR SUPPORTING DECISIONS MAKING ON TECHNICAL REGULATION IN BUILDING UNDER UNCERTAINTY CONDITIONS
}

\author{
Dmytro Isaienko \\ Confederation of Builders of Ukraine \\ 4 Bekhterevsky lane, Kyiv, Ukraine, 04053 \\ d.isaenko@ukr.net \\ Volodymyr Scochko \\ Department of Architectural Structures \\ Kyiv National University of Construction and Architecture \\ 31 Povitroflotsky ave., Kyiv, Ukraine, 03037 \\ vladimir.and.friends@gmail.com
}

\begin{abstract}
The main aim of the work is to elaborate algorithms and structure of data of the intellectual system of decisions making, able to provide functioning of the organizational-technical system of technical regulation in building under uncertainty conditions. The ability of intellectual systems to function under uncertainty conditions of different types is provided by using methods of indistinct mathematics and organization of a data structure, formed for revealing uncertainty automatically. The main attention in the article is paid to forming a data structure and algorithm for revealing uncertainty, caused by excessive information. The material of the research is information, contained in normative documents, according to which the technical regulation of the Ukrainian building branch is realized. It is especially urgent to reveal conflicts of parameters and rules, connected with reformation of the legislation in a part, related to the technical regulation of the branch. The automatic revelation of uncertainty that results in a discordance or conflict of parameters and rules, essentially facilitates elaboration of project documents and realization of expert evaluations at stages of building and exploitation of unique objects. But introduction of such intellectual systems allows to raise a speed and reliability of the work of other systems of the documents' circulation under transformation conditions essentially. The scientific novelty of the work is in using models of indistinct mathematics at formalizing norms and rules of the technical regulation in building and elaborating methods of their processing by the intellectual system of making decisions. The results of the work are demonstrated on the example of determination of a technical regulation parameter at excessive information, manifested in the presence of more than one normative document with instructions for determination of one regulation parameter. The probation and adaptation of norms and rules are realized in the legislative regulation of the activity in the Ukrainian building branch under conditions of changes, directed on improving the city-planning activity according to world standards.
\end{abstract}

Keywords: building branch, conflict of rules, data processing, organizational-technical system, technical regulation.

\section{Introduction}

One of most urgent problems in the branch of technical regulation in building and architecture is the presence of conflicts in instructions and principles of determining calculating regulation parameters. Such problem appears at transforming the organizational-technical system of technical regulation, connected with the transfer from a prescribing method of standardization to a parametric one. The accumulation of problems, connected with changes in standardization and regulation of licensing-conciliatory procedures in building according to world standards, favors [1, 2]:

- the growth of the demand for unique buildings and edifices;

- the change of requirements to influences on the external environment and priorities at forming the living environment;

- the introduction of changes to some legislative acts;

- the change of the raw material base for building materials;

- the development of designing and building technologies. 
At that different types of uncertainty appear that result in a necessity to create additional normative documents for explaining an order of actions in a case of uncertainty. Their accumulation complicates the process of technical regulation in whole and may cause conflicts of parameters and rules in the building branch.

\section{Aim of research}

It is modeling of the work of the intellectual system for supporting decisions making, able to provide functioning of the organizational-technical system of technical regulation under uncertainly conditions, caused by excessive information.

\section{Materials and methods of research}

The material of the research is information, contained in normative documents, according to which the technical regulation of the building branch is realized.

The analysis of the modern condition of the organizational-technical scheme of technical regulation in the Ukrainian building branch has demonstrated that the system of existent norms and rules of this branch contains different types of uncertainty [2, 3]. Causes of appearing, mathematical models and methods, which algorithms of the work of supporting systems for decisions making are based on, may be different and depend on an uncertainty type.

The classification of uncertainty of norms and rules for the technical regulation in the building branch by the type of existent information is demonstrated on Fig. 1.

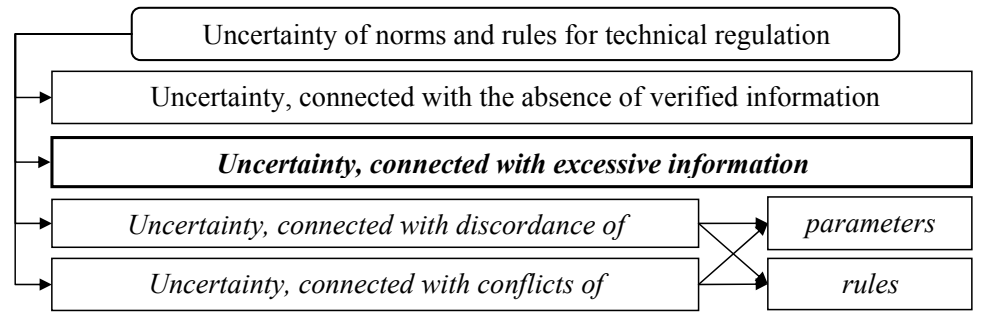

Fig. 1. Classification of uncertainty by the type of existent information

Uncertainty, connected with excessive information is in the absence of instructions for determining some regulation parameters or realization principles of procedures and operations in different normative documents.

The elaboration of methods and algorithms of the automatic revelation of conflict norms and rules at forming project documents, maintenance of building and exploitation of objects needs a correspondent understanding, systematization and structurization of documents.

Models and methods of indistinct mathematics are used in the work for solving the problem of the adequate presentation of norms and rules $[4,5]$.

In the first turn each element of the set of documents, destined for the technical regulation of a certain direction of the building branch's activity, is formalized as the vector:

$$
\{A\}^{T}=\left\{A_{j}\right\}=\left\{A_{1}, A_{2}, \ldots, A_{n}\right\}
$$

Each coordinate $A_{j}(j=1, \ldots, n)$ of which corresponds to one normative document, $n$ - number of documents; $\mathrm{T}$ - transposition operation.

After that the set of conflict norms and rules, in further subjected to decomposition and comparison, is taken from the set of formalized documents [3]. But work [3] pays the main attention to the problem of overcoming uncertainty, connected with rules that have identical conditions and different conclusions.

This work is devoted to the processing of uncertainty, connected with the presence of procedures and operations for determining one parameter in more than one normative document. For realizing the procedure of selection of the set of uncoordinated or conflict norms and rules, the regulation parameters are given as the vector $\{\mathrm{B}\}$ : 


$$
\{\mathrm{B}\}^{\mathrm{T}}=\left\{\mathrm{B}_{\mathrm{i}}\right\}=\left\{\mathrm{B}_{1}, \mathrm{~B}_{2}, \ldots, \mathrm{B}_{\mathrm{m}}\right\}
$$

where $m$ - number of correspondent parameters.

Each element of the vector $\{B\}$ corresponds to one calculating value or one rule of the technical regulation.

For realizing fast algorithms for searching for information in the set of documents $\{A\}$, according to which $\{\mathrm{B}\}$ parameters are determined, data (1), (2) are structured in Table 1 [6-8].

Table 1

Fragment of the data structure of the technical regulation system

\begin{tabular}{c|cccc}
\hline \multicolumn{1}{c}{$\mathbf{D}$} & $\mathbf{A}_{1}$ & $\mathbf{A}_{1}$ & $\cdots$ & $\mathbf{A}_{\mathbf{n}}$ \\
\hline $\mathrm{B}_{1}$ & $\mathrm{~B}_{1} \vee 0$ & $\mathrm{~B}_{1} \vee 0$ & $\ldots$ & $\mathrm{B}_{1} \vee 0$ \\
$\mathrm{~B}_{2}$ & $\mathrm{~B}_{2} \vee 0$ & $\mathrm{~B}_{2} \vee 0$ & $\ldots$ & $\mathrm{B}_{2} \vee 0$ \\
$\cdots$ & $\ldots$ & $\ldots$ & $\cdots$ \\
$\mathrm{B}_{\mathrm{m}}$ & $\mathrm{B}_{\mathrm{m}} \vee 0$ & $\mathrm{~B}_{\mathrm{m}} \vee 0$ & $\ldots$ & $\mathrm{B}_{\mathrm{m}} \vee 0$ \\
\hline
\end{tabular}

Each line of Table 1 contains one parameter $\mathrm{B}_{\mathrm{i}}$ of the certain direction, each column $\mathrm{A}_{\mathrm{j}}$ corresponds to the normative document that includes the set of parameters $\mathrm{B}_{\mathrm{i}}$, and symbol «V» means the operation of disjunction - «or».

The systematization of information is realized according to the priority $\mathrm{PA}_{\mathrm{j}}$ of the determining rule or calculating method of the parameter $\mathrm{B}_{\mathrm{i}}$ in documents $\mathrm{A}_{\mathrm{j}}$, established based on ranging results [9]:

$$
\mathrm{PA}_{\mathrm{i}, 1}<\cdots<\mathrm{PA}_{\mathrm{i}, \mathrm{a}-1}<\mathrm{PA}_{\mathrm{i}, \mathrm{a}}
$$

or

$$
\mathrm{PA}_{\mathrm{i}, 1}>\mathrm{PA}_{\mathrm{i}, 2}>\cdots>\mathrm{PA}_{\mathrm{i}, \mathrm{a}} .
$$

If documents have the same priority at that:

$$
\mathrm{PA}_{\mathrm{i}, 1}<\cdots<\mathrm{PA}_{\mathrm{i}, \mathrm{a}-1}=\mathrm{PA}_{\mathrm{i}, \mathrm{a}}
$$

or

$$
\mathrm{PA}_{\mathrm{i}, 1}=\mathrm{PA}_{\mathrm{i}, 2}>\cdots>\mathrm{PA}_{\mathrm{i}, \mathrm{a}} .
$$

Ranging results are subjected to the expert thought.

The information, contained in Table 1 may be represented as the matrix [K], each element of which is found according to [9]:

$$
K_{i, j}=\left\{\begin{array}{l}
1 \rightarrow D_{i, j}=B_{j} \\
0 \rightarrow D_{i, j}=0
\end{array} \quad(i=1,2, \ldots, m ; j=1,2, \ldots, n) .\right.
$$

That is:

- «1» - if the element $D_{i, j}$ in the matrix D equals $B_{i}$;

$-\ll 0 »-$ if the element $\mathrm{D}_{\mathrm{i}, \mathrm{j}}$ in the matrix $\mathrm{D}$ equals null.

The symbol « $\rightarrow »$ means implication (logic conclusion).

If the normative base, responsible for the technical regulation, is perfect, the matrix $[\mathrm{K}]$ : 


$$
\mathrm{K}=\left(\begin{array}{ccc}
\mathrm{K}_{1,1} & \ldots & \mathrm{K}_{1, \mathrm{n}} \\
\vdots & \ddots & \vdots \\
\mathrm{K}_{\mathrm{m}, 1} & \ldots & \mathrm{K}_{\mathrm{m}, \mathrm{n}}
\end{array}\right)=\left(\begin{array}{ccc}
1 \vee 0 & \ldots & 1 \vee 0 \\
\vdots & \ddots & \vdots \\
1 \vee 0 & \ldots & 1 \vee 0
\end{array}\right)
$$

Must correspond to conditions [9]:

1. The sum of elements of each line of the matrix [K] doesn't exceed 1:

$$
\mathrm{a}=\sum_{\mathrm{j}=1}^{\mathrm{n}} \mathrm{K}_{\mathrm{i}, \mathrm{j}} \leq 1,(\mathrm{i}=1,2, \cdots \mathrm{m})
$$

2. The sum of the elements of each column of the matrix $[\mathrm{K}]$ doesn't exceed the number of the technical regulation parameters $\mathrm{m}$ :

$$
\mathrm{b}=\sum_{\mathrm{i}=1}^{\mathrm{m}} \mathrm{K}_{\mathrm{i}, \mathrm{j}} \leq \mathrm{m}, \quad(\mathrm{i}=1,2, \cdots \mathrm{m}) .
$$

3. The sum of all elements of the matrix [K] doesn't exceed the number of the technical regulation parameters $\mathrm{m}$ :

$$
\mathrm{c}=\sum_{\mathrm{i}=1}^{\mathrm{m}} \sum_{\mathrm{j}=1}^{\mathrm{n}} \mathrm{K}_{\mathrm{i}, \mathrm{j}} \leq \mathrm{m}
$$

If one of conditions (7)-(9) is not satisfied, the set of normative documents contains conflicts that may cause problems and mistakes at solving problems of the technical and juridical type $[10,11]$.

\section{1. Calculating experiments}

One of main indicators of uncertainty, connected with excessive information is breaking of condition (7). Just this condition indicates the presence of several independent methods of fixing or calculation of a technical regulation parameter, determined by more than one normative document. Such situation complicates the work of the system and may cause a conflict of parameters or rules.

The problem is solved by revealing and excluding excessive information or coordinating conflict one and provides realization of the algorithm:

1) to establish the priority of documents $A_{j}$, according to which the parameter $B_{i}$ is found;

2) to involve experts, if documents with the same priority are present that is reflected by (4);

3) to reflect the priority of the parameters as the dependence:

$$
B_{i}=f\left(B_{1}, B_{2}, \ldots B_{j-1}, B_{j}, B_{j+1} \ldots, B_{r}\right),\left(j \neq i ; j=1,2, \ldots r_{i, j}\right)
$$

1. To structure the data as Fig. 2.

\begin{tabular}{|c|c|c|c|}
\hline$P D$ & $A_{1}$ & $A_{2}$ & $A_{3}$ \\
\hline$B_{1}$ & $B_{1}=$ const $_{1}$ & 0 & 0 \\
\hline$B_{2}$ & $B_{2}=f\left(B_{1}\right)$ & 0 & 0 \\
\hline$B_{3}$ & 0 & 0 & $B_{3}=f\left(B_{1}, B_{2}, B_{4}\right)$ \\
\hline$B_{4}$ & 0 & $B_{4}=$ const $_{4}$ & 0 \\
\hline$B_{5}$ & $B_{5}=$ const $_{5}$ & 0 & $B_{5}=f\left(B_{1}, B_{2}, B_{3}, B_{4}\right)$ \\
\hline
\end{tabular}

Fig. 2. Example of the table of the ranging priority reflection

2. To replace determination procedures of the conflict parameter or rule by a reference to more priority document. 
Fig. 2 demonstrates the example of the ranging documents' priority refection (PD), determined in p. 1 by rule (3), and cursors show the determination succession of the technical regulation parameters and the conflict of rules for determining the parameter $\mathrm{B}_{5}$.

The scheme of revelation of excessive information and solution of conflicts of parameters and rules in documents, according to which the technical regulation in the building branch is realized, is presented on Fig. 3.

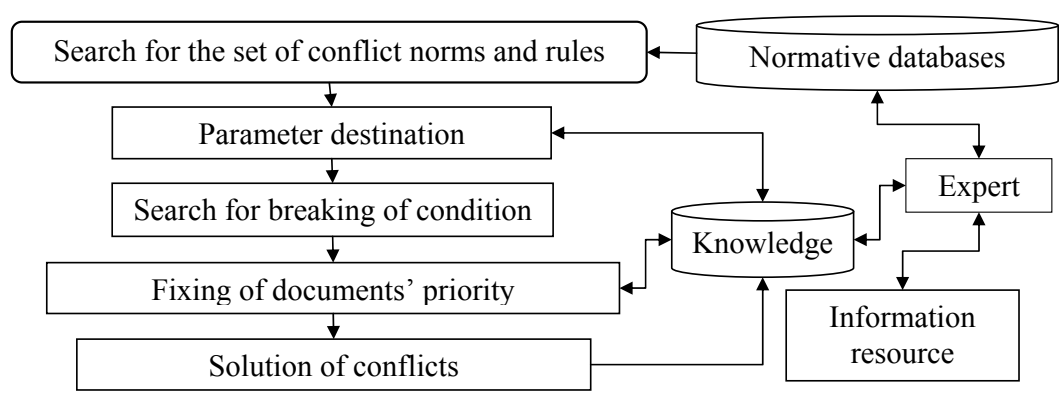

Fig. 3. Scheme of revelation of excessive information and solution of conflicts

At solving a conflict for determining a parameter, the most priority document is selected.

\section{Results}

The logic of the system of decisions making that functions at the presence of excessive information by the described algorithm is presented on the example, reflected on Fig. 2. The last line of the table doesn't satisfy condition (7). It means that there is a necessity to correct one of the normative documents $\mathrm{A}_{1}$ or $\mathrm{A}_{3}$. At that it must be understood what corrections must be introduced in the technical regulation system for determining or calculating the parameter $\mathrm{B}_{5}$.

It is logical to exclude the parameter $\mathrm{B}_{5}$ from the document $\mathrm{A}_{1}$, because in the document $\mathrm{A}_{3}$ this parameter is determined based on the functional dependence on all 4 other parameters of technical regulation $\mathrm{B}_{1}, \mathrm{~B}_{2}, \mathrm{~B}_{3}$ and $\mathrm{B}_{4}$, whereas in the document $\mathrm{A}_{1}$ this parameter is determined forcedly. But logical considerations are insufficient in such cases.

The numerical analysis of the technical regulation parameters with a possibility to compare the correspondent parameters is based on the processed matrix [L]:

$$
\mathrm{L}=\left(\begin{array}{ccc}
\mathrm{L}_{1,1} & \ldots & \mathrm{L}_{1, \mathrm{n}} \\
\vdots & \ddots & \vdots \\
\mathrm{L}_{\mathrm{m}, 1} & \ldots & \mathrm{L}_{\mathrm{m}, \mathrm{n}}
\end{array}\right)=\left(\begin{array}{ccc}
\left(\mathrm{r}_{1,1}\right) \vee 1 \vee 0 & \ldots & \left(\mathrm{r}_{1, \mathrm{n}}\right) \vee 1 \vee 0 \\
\vdots & \ddots & \vdots \\
\left(\mathrm{r}_{\mathrm{m}, 1}\right) \vee 1 \vee 0 & \ldots & \left(\mathrm{r}_{\mathrm{m}, \mathrm{n}}\right) \vee 1 \vee 0
\end{array}\right)
$$

The elements of the matrix [L] are determined as following:

$$
L_{i, j}=\left\{\begin{array}{cccc}
1, & \rightarrow & D_{i, j}=\text { const }_{i}, \\
r_{i, j}+1, & \rightarrow & D_{i, j}=f\left(B_{1}, B_{2}, \ldots B_{k 1}, B_{k}, B_{k+1} \ldots, B_{r}\right)_{i}, \\
0, & \rightarrow & D_{i, j}=0,
\end{array} \quad\left(\begin{array}{c}
i=1,2, \cdots m ; \\
j=1,2, \cdots n ; \\
i \neq k=1,2, \cdots r_{i, j}
\end{array}\right)\right.
$$

For the example from Fig. 2, the values $r_{i, j}$, are:

1) $r_{1,1}=1$, because $B_{1}=$ const $_{1}$;

2) $r_{2,1}=1+1=2$, because $B_{2}=f\left(B_{1}\right)$;

3) $\mathrm{r}_{5,1}=1$, because $\mathrm{B}_{5}=$ const $_{5}$;

4) $r_{4,2}=1$, because $B_{4}=$ const $_{4}$;

5) $r_{3,3}=3+1=4$, because $B 3=f\left(B_{1}, B_{2}, B_{4}\right)$;

6) $r_{5,3}=4+1=5$, because $B_{5}=f\left(B_{1}, B_{2}, B_{3}, B_{4}\right)$. 
After the substitution and exclusion from data, excessive as to the parameter $\mathrm{B}_{5}$ with the priority $\mathrm{r}_{5,1}=1\left(\mathrm{r}_{5,1}<\mathrm{r}_{5,3}\right)$ the matrix [L] looks as:

$$
\mathrm{L}=\left(\begin{array}{lll}
1 & 0 & 0 \\
2 & 0 & 0 \\
0 & 0 & 0 \\
0 & 0 & 4 \\
0 & 1 & 0 \\
1 & 0 & 5
\end{array}\right)=\left(\begin{array}{lll}
1 & 0 & 0 \\
2 & 0 & 0 \\
0 & 0 & 4 \\
0 & 1 & 0 \\
0 & 0 & 5
\end{array}\right)=\left[\mathrm{L}^{\prime}\right]
$$

where $\left[\mathrm{L}^{\prime}\right]$ - corrected matrix, each element of which forms by the principle:

$$
L_{i, j}^{\prime}=\left\{\begin{array}{ccc}
L_{i, j}, & \rightarrow & L_{i, j}>L_{i, k}, j \neq k=1,2, \ldots j-1, j-1, \ldots n ; \\
0, & \rightarrow & L_{i, j}<L_{i, k}, j \neq k=1,2, \ldots j-1, j-1, \ldots n ;
\end{array}\left(\begin{array}{c}
i=1,2, \cdots m ; \\
j=1,2, \cdots n
\end{array}\right),\right.
$$

Now the matrix $\left[\mathrm{L}^{\prime}\right]$, in general looks as:

$$
\left[\mathrm{L}^{\prime}\right]=\left(\begin{array}{ccc}
\mathrm{L}_{1,1}^{\prime} & \ldots & \mathrm{L}_{1, \mathrm{n}}^{\prime} \\
\vdots & \ddots & \vdots \\
\mathrm{L}_{\mathrm{m}, 1}^{\prime} & \ldots & \mathrm{L}_{\mathrm{m}, \mathrm{n}}^{\prime}
\end{array}\right)=\left(\begin{array}{ccc}
\mathrm{L}_{1,1} \vee 0 & \ldots & \mathrm{L}_{1, \mathrm{n}} \vee 0 \\
\vdots & \ddots & \vdots \\
\mathrm{L}_{\mathrm{m}, 1} \vee 0 & \ldots & \mathrm{L}_{\mathrm{m}, \mathrm{n}} \vee 0
\end{array}\right)
$$

Form (14) may be used for determining the global priority of the technical regulation parameters. For that it is necessary to calculate the sums of the lines of the matrix [L'], and to form the priority vector $\{\mathrm{PB}\}$ :

$$
\{\mathrm{PB}\}^{\mathrm{T}}=\left\{\begin{array}{llll}
\mathrm{PB}_{1} & \mathrm{~PB}_{2} & \cdots & \mathrm{PB}_{\mathrm{m}}
\end{array}\right\}
$$

where

$$
\mathrm{PB}_{\mathrm{i}}=\sum_{\mathrm{j}=1}^{\mathrm{n}} \mathrm{L}_{\mathrm{i}, \mathrm{j}}^{\prime},(\mathrm{i}=1,2, \cdots \mathrm{m})
$$

Especially, for matrix (12) the vector $\{\mathrm{PB}\}$ looks as:

$$
\{\mathrm{PB}\}^{\mathrm{T}}=\left\{\begin{array}{lllll}
1 & 2 & 4 & 1 & 5
\end{array}\right\} .
$$

After forming the vector $\{\mathrm{PB}\}$ and sorting the elements of the matrixes $[\mathrm{K}]$ and $\left[\mathrm{L}^{\prime}\right]$, it becomes possible to range the technical regulation parameters.

The result of the described transformations is the vector $\left\{\mathrm{PB}^{*}\right\}$ and matrixes $\left[\mathrm{K}^{*}\right]$ and $\left[\mathrm{L}^{*}\right]$ :

$$
\begin{aligned}
& \mathrm{PB}^{*}{ }_{1} \quad \mathrm{~PB}_{\mathrm{m}-1}^{*} \quad \mathrm{~PB}_{\mathrm{m}}^{*}, \quad \mathrm{~PB}^{*} \mathrm{~PB}^{*}{ }_{2} \quad \mathrm{~PB}_{\mathrm{m}}^{*} \text {, } \\
& \left\{\mathrm{K}^{*}\right\}_{1}<\cdots<\left\{\mathrm{K}^{*}\right\}_{\mathrm{m}-1}<\left\{\mathrm{K}^{*}\right\}_{\mathrm{m}} \text {, or }\left\{\mathrm{K}^{*}\right\}_{1}>\left\{\mathrm{K}^{*}\right\}_{2}>\cdots>\left\{\mathrm{K}^{*}\right\}_{\mathrm{m}} \text {, } \\
& \left\{\mathrm{L}^{*}\right\}_{1} \quad\left\{\mathrm{~L}^{*}\right\}_{\mathrm{m}-1} \quad\{\mathrm{~L} *\}_{\mathrm{m}}, \quad\left\{\mathrm{L}^{*}\right\}_{1} \quad\left\{\mathrm{~L}^{*}\right\}_{2} \quad\{\mathrm{~L} *\}_{\mathrm{m}} .
\end{aligned}
$$

At that functional connections of the "bottom-up" type will not appear in the tables "D" and "PD".

After sorting by growth, formulas (17) and (12) look as:

$$
\left\{\mathrm{PB}^{*}\right\}^{\mathrm{T}}=\left\{\begin{array}{lllll}
1 & 1 & 2 & 4 & 5
\end{array}\right\}
$$


and

$$
\mathrm{L}^{*}=\left(\begin{array}{ccc}
1 & 0 & 0 \\
0 & 1 & 0 \\
2 & 0 & 0 \\
0 & 0 & 4 \\
0 & 0 & 5
\end{array}\right)
$$

It must be noted, that at excluding some conflict technical regulation parameter from one document, it is necessary to analyze conditions and recommendations, present in less priority one. Such analysis prevents the unreasonable shift of instructions to more priority document that may result in losing a content or distinctness of information. At that the correction of both conflict documents may result in contradictions jut in more priority document.

Just that is why step 5 of the algorithm of the revelation and exclusion of excessive information of coordination of conflict one are left for experts at this stage of elaborating the system.

\section{Conclusions}

1. The use of models and methods of indistinct mathematics at formalizing documents gives a possibility to improve the work of the organizational-technical system of technical regulation at the expanse of automation of text information processing.

2. The offered matrix data structure facilitates the procedure of searching for excessive information in documents on technical regulation in the building branch.

3. The algorithm of revelation and solution of conflicts is grounded on comparison of the documents' priority. Just that is why further researches are planned to be devoted to the analysis of algorithms for searching and sorting text information.

\section{References}

[1] Regulation (EU) No 305/2011 of the European Parliament and of the Council of 9 March 2011 laying down harmonised conditions for the marketing of construction products and repealing Council Directive 89/106/EEC Text with EEA relevance.

[2] Isayenko, D. V. (2017). Zakonodavche rehulyuvannya diyal'nosti v budivel'niy haluzi. Osoblyvosti svitovoho dosvidu ta Yevropeys'koho pidkhodu dlya vyznachennya priorytetiv pry formuvanni zhyttyevoho. Budivel'ne vyrobnytstvo, 63, 11-15.

[3] Isaienko, D., Ploskyi, V., Terenchuk, S. (2018). Formation of the fuzzy knowledge of the knowledge support system for decision-making technical regulation of construction activity. Management of Development of Complex Systems, 35, 168-174.

[4] Terenchuk, S., Pashko, A., Yeremenko, B., Kartavykh, S., Ershova, N. (2018). Modeling an intelligent system for the estimation of technical state of construction structures. Eastern-European Journal of Enterprise Technologies, 3 (2 (93)), 47-53. doi: http://doi.org/10.15587/1729-4061.2018.132587

[5] Kulikov, P., Ploskiy, V., Skochko, V. (2014). The Principles of Discrete Modeling of Rod Constructions of Architectural Objects. Motrol, 16 (8), 3-10.

[6] Thomas, H., Leiserson, C. E., Rivest, R. L., Stein, C. (2003). Introduction to Algorithms. Cambridge: MIT Press.

[7] Graybill, F. A. (1969). Introduction to matrices with applications in statistics. Belmont: Wrels Worth Publishing Company, Inc., 372.

[8] Skochko, V., Ploskyi, V. (2018). Morphogenesis and adjustment of flat rod structures. USEFUL Online Journal, 2 (2), 8-26. doi: http://doi.org/10.32557/useful-2-2-2018-0002

[9] Kuprenas, J. A. (2003). Implementation and performance of a matrix organization structure. International Journal of Project Management, 21 (1), 51-62. doi: http://doi.org/10.1016/s0263-7863(01)00065-5

[10] Skochko, V. (2018). Determination of support reactions of rod constructions obtained by morphogenesis. USEFUL Online Journal, 2 (3), 29-42. doi: http://doi.org/10.32557/useful-2-3-2018-0005

[11] Laslo, Z., Goldberg, A. I. (2008). Resource allocation under uncertainty in a multi-project matrix environment: Is organizational conflict inevitable? International Journal of Project Management, 26 (8), 773-788. doi: http://doi.org/10.1016/j.jproman.2007.10.003 